Check for updates

Cite this: RSC Adv., 2017, 7, 40640

\title{
Chiral and non-conjugated fluorescent salen ligands: AIE, anion probes, chiral recognition of unprotected amino acids, and cell imaging applications $\dagger$
}

\author{
Guangyu Shen, Fei Gou, Jinghui Cheng, Xiaohong Zhang, Xiangge Zhou (DD \\ and Haifeng Xiang (iD)*
}

Natural products are usually non-conjugated and chiral, but organic luminescent materials are commonly polycyclic aromatic molecules with extended $\pi$-conjugation. In the present work, we combine with the advantages of non-conjugation and chirality to prepare a series of novel and simple salen ligands (41 samples), which have a non-conjugated and chiral $(S, S)$ and $(R, R)$ cyclohexane or 1,2-diphenylethane bridge but display strong blue, green, and red aggregation-induced emission (AIE) with large Stokes shifts (up to $186 \mathrm{~nm}$ ) and high fluorescence quantum yields (up to 0.35). Through hydrogen and halogen bonds, these flexible salen ligands can be used as universal anion probes and chiral receptors of unprotected amino acids (enantiomeric selectivity up to 0.11) with fluorescence quantum yields up to 0.29 and 0.27, respectively. Moreover, the effects of different chiral bridges on the molecule arrangement, $\mathrm{AIE}$, and anion and chiral recognition properties are also explored, which provide unequivocal insights for the design of non-conjugated chiral and soft fluorescent materials.

Received 27th July 2017

Accepted 12th August 2017

DOI: $10.1039 / \mathrm{c} 7 \mathrm{ra0} 8267 \mathrm{c}$

rsc.li/rsc-advances
Organic luminescent (fluorescent or phosphorescent) materials $^{6}$ are commonly polycyclic aromatic molecules with extended $\pi$-electron conjugation, but these rigid materials might suffer some disadvantages, such as the synthesis difficulty, poor solubility, and fluorescence aggregation-caused quenching $^{7}$ (ACQ). On the other hand, non-conjugated soft materials that might have a better solubility, lower cost, higher flexibility, lower cytotoxicity, better biocompatibility, and naturally occurring, ${ }^{8}$ are usually taken for granted as nonemissive materials. Until recently, some non-conjugated materials, such as 1,1,2,2-tetraphenylethane, ${ }^{9}$ poly[(maleic anhydride)-alt-(vinyl acetate)], ${ }^{10}$ polyisobutene succinic anhydrides and imides, ${ }^{11}$ and steroidal saponin digitonin, ${ }^{12}$ were reported to show amazing ultraviolet (UV) or blue aggregation-induced emission (AIE)..$^{9,13}$ Our research work continuously focus on the synthesis, optical properties, and sensing applications of $N, N^{\prime}$-bis(salicylidene)ethylenediamine (salen), a particular class of salicylaldehyde-based bis-Schiff base (Fig. 1), owing to its facile preparation, good stability, and rich optical properties. $^{\boldsymbol{7 b}, \mathbf{1 4}}$ Our recently work demonstrated that step-like salen ligands ${ }^{14 g}\left(R-\mathrm{C}_{n}\right)$ and tripod-like tri-Schiff bases ${ }^{15}$ (TSBs, Fig. 1a) linking with non-conjugated long alkyl bridges display strong red-green-blue (RGB) AIE. If chiral $(S, S)$ and $(R, R)$ cyclohexane or 1,2-diphenylethane bridges are employed, it is easy to prepare chiral salen ligands (Fig. 1b). These non-conjugated chiral ligands are widely used as asymmetric catalysts, ${ }^{16}$ and they are deemed to be non-emissive and used as turn-on fluorescence 
(a)

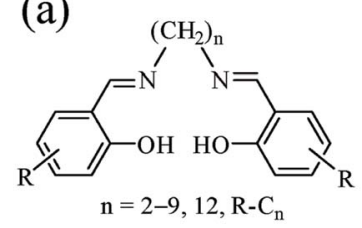

(b)<smiles>[Y]c1ccc(C=N)cc1O</smiles><smiles>C=C1CCCCC1</smiles>

probes for detecting metal ions. ${ }^{17}$ Moreover, non-conjugated soft materials might be used as anion probes, because they are flexible and might have multiple and strong intermolecular interactions with anions through hydrogen bonds. ${ }^{15}$ Particularly, the effects of different chiral bridges on the molecule arrangement, AIE, and chiral recognition properties are still unexplored. Herein, we demonstrate a novel and simple class of colorful chiral salen ligands ( 41 samples, Fig. 1b) that are linked by a non-conjugated cyclohexane (Cy) or 1,2-diphenylethane (diPh) bridge but have strong AIE and potential applications in cell imaging and recognition of anion and chiral unprotected amino acids.

\section{Results and discussion}

\section{Synthesis and characterization}

All salen ligands were reasonably easy to synthesize by the condensation of primary diamine with 2 equivalents of salicylaldehyde precursor in ethanol under refluxing condition. ${ }^{14}$ Most salen ligands have a bad solubility in petroleum ether, hexane, and water but a good solubility in $\mathrm{CH}_{3} \mathrm{CN}, \mathrm{CH}_{2} \mathrm{Cl}_{2}$, DMF, and DMSO. All salen ligands either in solution or in solid state are stable within several months under air. For most salen ligands, good-quality single crystals can be obtained by the method of slow solvent diffusion/evaporation $\left(\mathrm{CH}_{2} \mathrm{Cl}_{2} /\right.$ hexane $)$. For the purpose of comparison, the reference substance $\mathrm{C}_{2}$ (ref. 14g) (Fig. 1a) was prepared as well.

\section{Photophysical and AIE properties}

The UV/visible absorption and fluorescence data of all synthesized Cys and diPhs at room-temperature are listed Tables S1, S2, Fig. S1, and S2 (in ESI $\dagger$ ). Since the photophysical and AIE properties of $(S, S),(R, R)$, and racemic salen ligands are similar, only racemic salen ligands are discussed in this section. As we expected, all salen ligands exhibit weak fluorescence in pure organic solvent of MeCN or DMSO (Tables S1-S3†). For example, racemic 3,5-Cl-Cy shows very weak blue fluorescence $(\Phi=0.010)$ in the dilute MeCN, because the dynamic intramolecular rotations (IRs) of central cyclohexane bridge in 3,5Cl-Cy molecules provide a possible way to non-radiatively annihilate its excited states and result in the absence of fluorescence consequently. However, if water is added into MeCN, the green fluorescence of 3,5-Cl-Cy is strengthened (Fig. 2), because 3,5-Cl-Cy molecules cannot be dissolved in water, which causes 3,5-Cl-Cy molecules to precipitate and aggregate. At the same time, adding water would red shift its absorption spectrum (Fig. S3 $\dagger$ ), which further confirms this aggregation. Its green fluorescence reaches the maximum $\left(\lambda_{\mathrm{em}}=511 \mathrm{~nm}, \Phi=\right.$ 0.064 ) with a large Stokes shift of $117 \mathrm{~nm}$, when the volume fraction $(f)$ of water is increased to $90 \%$. Furthermore, solid 3,5Cl-Cy displays strong green-yellow fluorescence $\left(\lambda_{\mathrm{em}}=532 \mathrm{~nm}\right.$, $\Phi=0.32$ ) under $360 \mathrm{~nm}$ UV lamp (Fig. 2 and 3). All these findings reveal the fact of its AIE nature.

All the salen ligands have stronger fluorescence in solid state or water than in organic solvents (Tables S1 and S2 $\dagger$ ). Most solid samples, such as crystals, powders, and casting films (Fig. S4†), exhibit not only red-shifted but also much stronger fluorescence compared with water samples (Fig. 3, Tables S1, and S2 $\dagger$ ), and thus we will focus on their solid AIE characteristics. As shown in Fig. 4, Tables S1, and S2, $\uparrow$ for solid salen ligands, different substituents have different effects on the emission peaks $\left(\lambda_{\mathrm{em}}: 474-565 \mathrm{~nm}\right)$ and colors (blue, green, and red). The presence of a $\pi$-extended system (Naph-Cy, $\lambda_{\mathrm{em}}=486 \mathrm{~nm}$ ) to the simplest $\mathbf{C y}\left(\lambda_{\mathrm{em}}=502 \mathrm{~nm}\right)$ leads to a blue shift in fluorescence spectra. On the other hand, electron-donating-OMe (3-OMe-Cy, $\left.\lambda_{\mathrm{em}}=523 \mathrm{~nm} ; \mathbf{5}-\mathbf{O M e}-\mathrm{Cy}, \lambda_{\mathrm{em}}=548 \mathrm{~nm}\right)$ or electron-accepting -F (3-F-Cy, $\left.\lambda_{\mathrm{em}}=509\right),-\mathrm{Cl}$ (3-Cl-Cy, $\lambda_{\mathrm{em}}=520 \mathrm{~nm}$; 3,5-Cl-Cy, $\left.\lambda_{\mathrm{em}}=532 \mathrm{~nm}\right)$, or $-\mathrm{NO}_{2}\left(3-\mathrm{NO}_{2}-\mathrm{Cy}, \lambda_{\mathrm{em}}=565 \mathrm{~nm} ; 3,5-\mathrm{NO}_{2}\right.$, $\lambda_{\mathrm{em}}=550 \mathrm{~nm}$ ) substituents result in red-shifted emission (Fig. 4

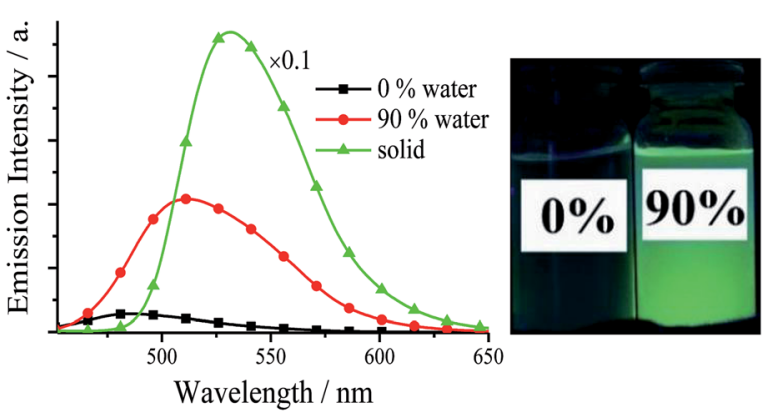

Fig. 2 Emission spectra and photographs (under $360 \mathrm{~nm}$ UV light) of $3,5-\mathrm{Cl}-\mathrm{Cy}$ in $\mathrm{MeCN}-\mathrm{H}_{2} \mathrm{O}$ with different $f$ values $\left(1.0 \times 10^{-5} \mathrm{~mol} \mathrm{dm}^{-3}\right)$ and solid. 


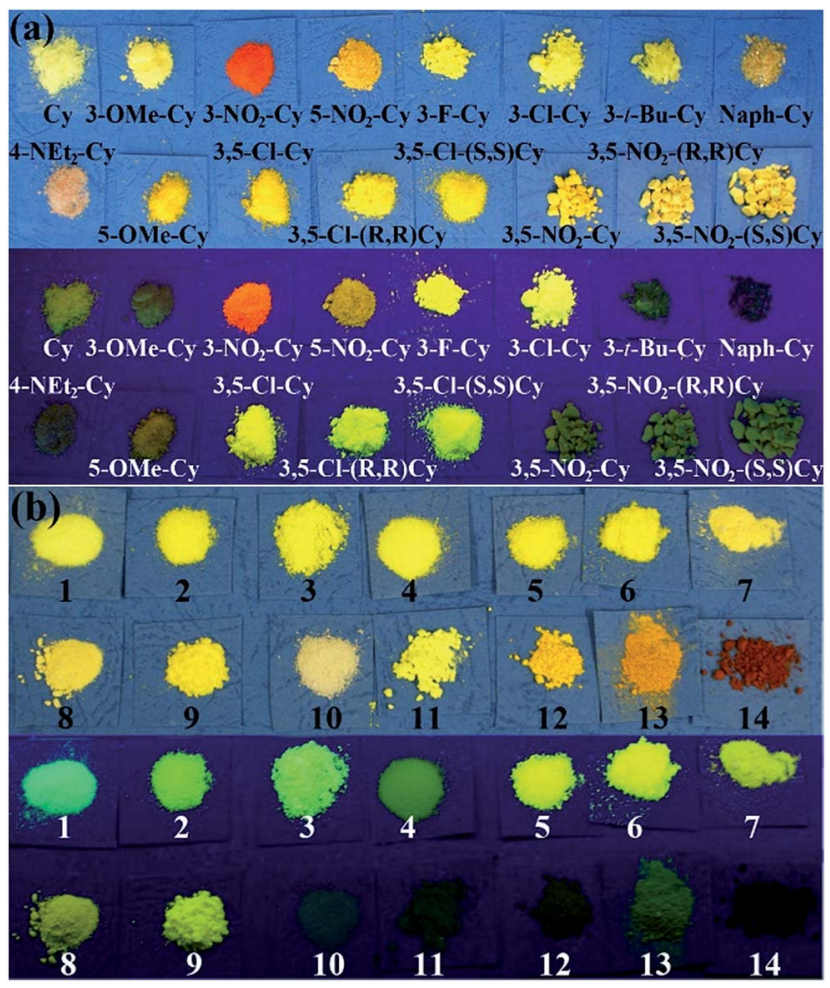

Fig. 3 Photographs (top: under room light, bottom: under $360 \mathrm{~nm}$ UV light) of Cys (a) and diPhs (b) $1=$ diPh, $2=3-\mathrm{F}-(R, R)-\mathrm{diPh}, 3=3-\mathrm{F}-$ $(S, S)$-diPh, $4=3$-Cl-diPh, $5=3-\mathrm{Cl}-(R, R)$-diPh, $6=3-\mathrm{Cl}-(S, S)$-diPh, $7=3,5-\mathrm{Cl}$-diPh, $8=3,5-\mathrm{Cl}-(R, R)-\mathrm{diPh}, 9=3,5-\mathrm{Cl}-(S, S)$-diPh, $10=4-$ $\mathrm{NEt}_{2}$-diPh; $11=$ Naph-diPh, $12=3-\mathrm{NO}_{2}-$ diPh, $13=5-\mathrm{NO}_{2}-$ diPh, $14=$ 3,5- $\mathrm{NO}_{2}$-diPh) powders.

and Table $\mathrm{S} 1 \dagger)$. A similar substituent effect was observed for solid diPhs (Fig. 4 and Table $\mathrm{S} 2 \dagger$ ), $R$ - $\mathrm{C}_{n}{ }^{14 g}$ and $\mathrm{TSBS}^{15}$ (Fig. 1a) as well, indicating that a substituent has a very obvious effect on $\lambda_{\text {em }}$ of these non-conjugated AIE-active materials.

All fluorescence quantum yields $(\Phi)$ (Tables S1 and S2†) of the aggregated salen ligands in water and solid state were

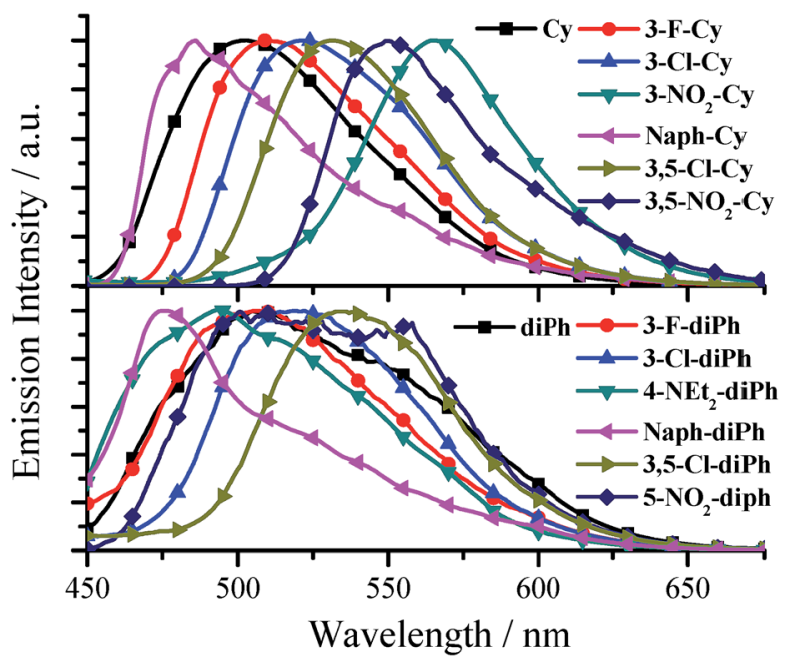

Fig. 4 Normalized emission spectra of some Cys and diPhs solids. measured by the optical dilute method of Demas and Crosby ${ }^{\mathbf{1 8}}$ with a standard of quinine sulfate $\left(\Phi_{\mathrm{r}}=0.55\right.$, quinine in $0.05 \mathrm{~mol} \mathrm{dm}^{-3}$ sulfuric acid) and an integrating sphere, respectively. Although the salen ligands with a non-conjugated linker have a small $\pi$-conjugated system, the fluorescence quantum yields of some salen ligands are unexpected high (up to 0.35 and 0.22 for Cys and diPhs, respectively, Tables S1 and $\mathrm{S} 2 \dagger)$. In general, the introduction of $-\mathrm{F}(3-\mathrm{F}-\mathrm{Cy}, \Phi=0.060$; 3-FdiPh, $\Phi=0.12$ ), -Cl (3-Cl-Cy, $\Phi=0.14$; 3,5-Cl-Cy, $\Phi=0.32$; 3-CldiPh, $\Phi=0.16$; 3,5-Cl-diPh, $\Phi=0.20)$ substituents to $\mathbf{C y}(\Phi=$ $0.018)$ or diPh $(\Phi=0.10)$ would improve its fluorescence quantum yield, but the presence of other substituents would bring positive or negative effects on fluorescence quantum yield. Combining with the previous results, ${ }^{14 g, 15}$ we can draw a conclusion that chlorination or fluorination is an much more efficient way to improve the fluorescence quantum yields of non-conjugated materials than those of $\pi$-conjugated materials.

\section{Mechanism of AIE}

The molecular structures and arrangements play a key role in AIE. For most AIE-active materials, they are $\pi$-conjugated molecules and stack closely with not only a short interplanar distance ( $d$, for plane molecules $\left.{ }^{\mathbf{1 4} f}\right)$ or intermolecular aromatic $\mathrm{H}_{\mathrm{Ar} \cdots \pi}$ hydrogen bonds (for non-plane molecules, such as silole ${ }^{19}$ or $\mathrm{TPE}^{20}$ ) but also weak intermolecular face-to-face $\pi-\pi$ interactions. The former can ensure to eliminate the molecular rotation, the later would prevent the formation of excimer. For non-conjugated AIE-active $R-\mathrm{C}_{n}$ (ref. $14 \mathrm{~g}$ ) and TSBs, ${ }^{15}$ however, the restriction of $\mathrm{C}-\mathrm{C}$ single bond rotations in the central alkyl chain bridges through some other non-covalent intermolecular interactions, such as $\mathrm{N} \cdots \mathrm{H}, \mathrm{O} \cdots \mathrm{H}, \mathrm{C} \cdots \mathrm{H}, \mathrm{H} \cdots \mathrm{H}, \mathrm{F} \cdots \mathrm{H}, \mathrm{Cl} \cdots \mathrm{H}$, and $\mathrm{Cl} \cdots \mathrm{Cl}$ must be considered as well.

In order to investigate the effect of molecule arrangements, the X-ray single crystal structures of $\mathbf{C y}{ }^{21}$ 3-F-Cy (CCDC 1551151), 3-F-(S,S)Cy (CCDC 1496280), 3-F-(R,R)Cy (CCDC 1496279), 3,5-Cl-Cy, ${ }^{22}$ 3-NO ${ }_{2}-(R, R) C y,{ }^{23}$ 3-F-diPh (CCDC 1551150), and 3-Cl-diPh (CCDC 1551147) are depicted in Fig. 5-7 and

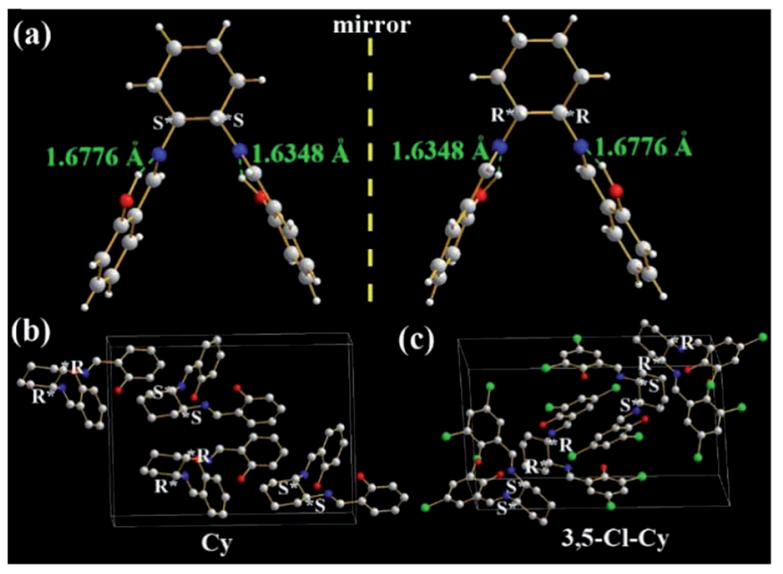

Fig. 5 X-ray single crystal structures and packing of $\mathrm{Cy}$ and 3,5-Cl-Cy molecules: (a) $(S, S)$ and $(R, R)$ enantiomers of $\mathrm{Cy}$; (b) and (c) packing in a unit cell ( $\mathrm{H}$ atoms are omitted). 


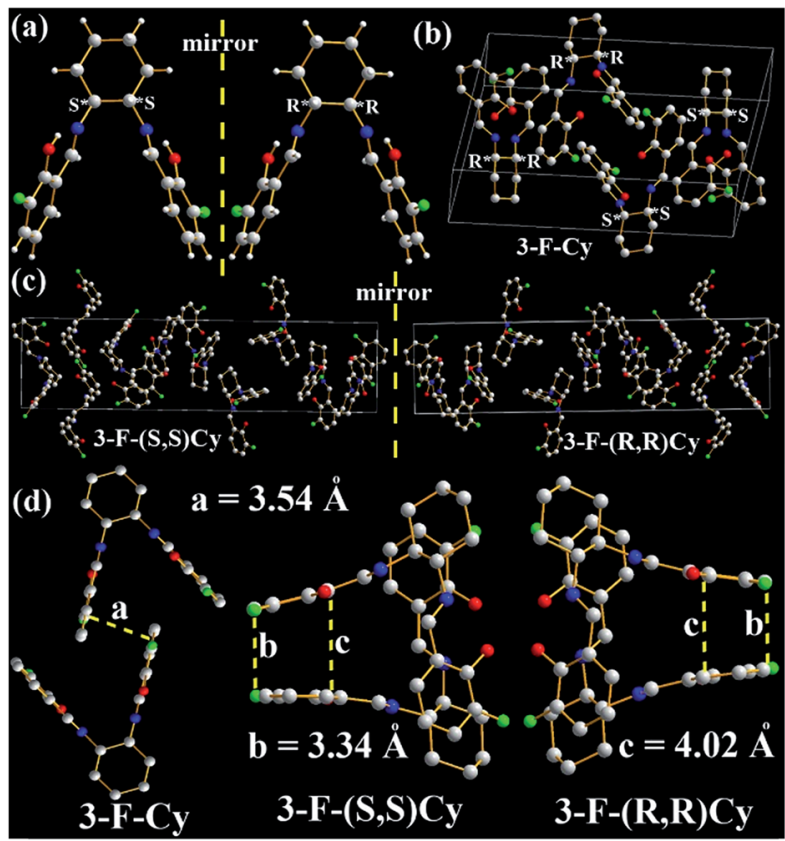

Fig. 6 X-ray single crystal structures and packing of 3-F-Cy, 3-F-(S,S) $\mathrm{Cy}$, and 3-F- $(R, R)$ Cy molecules: (a) $(S, S)$ and $(R, R)$ enantiomers; (b) and (c) packing in a unit cell ( $\mathrm{H}$ atoms are omitted); (d) intermolecular interactions of the two closest molecules ( $\mathrm{H}$ atoms are omitted).

S5-S18. $\dagger$ Unlike step-like $R-\mathrm{C}_{n}$ (ref. $14 g$ ) and tripod-like $\mathrm{TSBs}^{15}$ molecules, these Cys and diPhs molecules are $\mathrm{V}$ - and propellertype, respectively.

As expected, two intramolecular $\mathrm{N} \cdots \mathrm{H}$ hydrogen bonds (1.6776 and $1.6348 \AA$ ) between $\mathrm{H}(-\mathrm{OH})$ and $\mathrm{N}(\mathrm{C}=\mathrm{N})$ atoms are found in $\mathbf{C y}$ (Fig. 5a), which would eliminate free rotations of phenol rings. The dihedral angles between two panels of $\pi$ conjugated phenol rings are about $56.6^{\circ}$, resulting in its V-type molecular configuration and no intramolecular face-to-face $\pi-\pi$ interactions in one $\mathbf{C y}$ molecule. In dilute organic solution, it is obvious that the rotatable $\mathrm{C}-\mathrm{N}$ and $\mathrm{C}-\mathrm{C}$ single bonds in the central cyclohexane bridge afford a possible way to non-

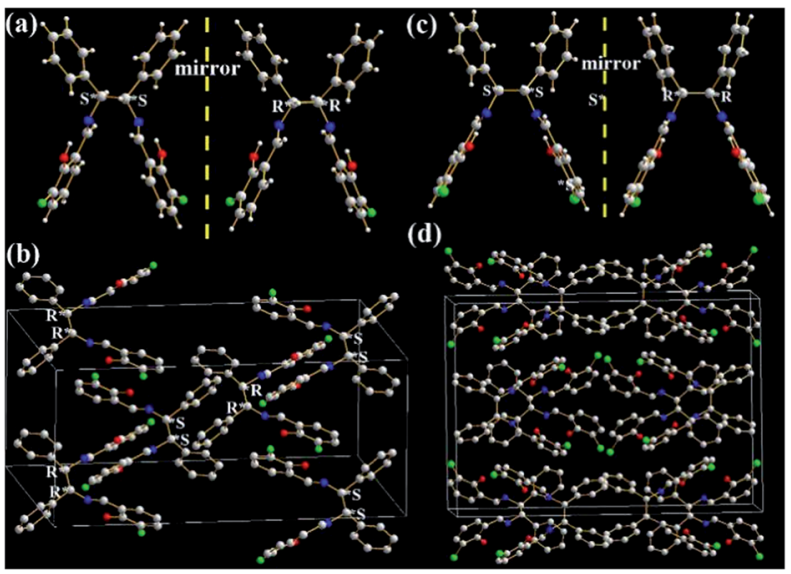

Fig. 7 X-ray single crystal structures and packing of 3-F-diPh $(a, b)$ and 3-Cl-diPh (c, d) molecules: (a) and (c) $(S, S)$ and $(R, R)$ enantiomers; (b) and (d) packing in a unit cell ( $\mathrm{H}$ atoms are omitted). radiatively annihilate its excited states and quench the fluorescence consequently. In the solid state, however, $\mathbf{C y}$ molecules exhibit a head (cyclohexane)-to-tail (phenol ring) orientation (Fig. 5b). No intermolecular face-to-face $\pi-\pi$ interactions (Fig. 5a, b, and S5 $\dagger$ ) are found between any neighboring $\mathbf{C y}$ molecules. On the contrary, many other strong intermolecular interactions including $\mathrm{H} \cdots \mathrm{H}(2.4578,2.5302,2.6280,2.7014$, $2.7544,2.7770,2.7896,2.8042,2.8886,2.9240$, and $2.9792 \AA$ ), $\mathrm{C} \cdots \mathrm{H}(2.8077$ and $2.8296 \AA)$, and $\mathrm{O} \cdots \mathrm{H}(2.8111 \AA)$ interactions are found in the two adjacent $\mathbf{C y}$ molecules (Fig. S5 $\dagger$ ). These above intramolecular and intermolecular interactions would help to restrain the IRs and lead to the presence of AIE consequently. Owing to the existence of chiral carbon atoms, two $(S, S)$ and $(R, R)$ enantiomers $(1: 1)$ are found in the single crystals of racemic Cy (Fig. 5a and b). The $R / S$-chirality-induced interactions between two enantiomers (Fig. $55 \dagger$ ) would help Cy molecules arrange in a tight head-to-tail orientation packing.

Similar two $(S, S)$ and $(R, R)$ enantiomers $(1: 1)$ are also found in the single crystals of racemic 3,5-Cl-Cy (Fig. 5 c, S6, and S7 $\dagger$ ), but 3,5-Cl-Cy molecules exhibit a different tail-to-tail orientation from $\mathbf{C y}$ molecules (Fig. 5c). The $R / S$-chirality of two enantiomers induce their phenol rings to pack together with a $d$ of $3.46 \AA$ (Fig. S6a $\dagger$ ) and little intermolecular face-to-face $\pi-$ $\pi$ interactions (overlaps in two benzene rings). At the same time, many other strong intermolecular interactions including $\mathrm{H} \cdots \mathrm{H}(2.6687,2.6899,2.8377,2.8587$, and $2.8978 \AA), \mathrm{O} \cdots \mathrm{H}$ (2.4244, 2.6160, 2.6374, 2.6849 $\mathrm{A})$, and $\mathrm{Cl} \cdots \mathrm{H}(2.8689$ and $2.8843 \AA$ ) interactions are found in the two adjacent 3,5-Cl-Cy molecules (Fig. S6c, d, and S7 $\dagger$ ). Moreover, strong $\mathrm{Cl} \cdots \mathrm{Cl}$ interactions (3.2848 A, Fig. S7c $\dagger$ ) are observed, because two benzene rings are packed together. The $\mathrm{F}$ and $\mathrm{Cl}$ atoms would help to induce intermolecular $\mathrm{F} \cdots \mathrm{H}, \mathrm{F} \cdots \mathrm{F}, \mathrm{Cl} \cdots \mathrm{O}, \mathrm{Cl} \cdots \mathrm{H}$, or $\mathrm{Cl} \cdots \mathrm{Cl}$ interactions (halogen bond ${ }^{24}$ ) that is one possible reason why chlorination or fluorination can improve fluorescence quantum yield (see later discussion). All these data are consistent with the fact that solid 3,5-Cl-Cy and its enantiomers have the highest $\Phi$ values $(0.32-0.35)$.

In order to evaluate the effects of different chiral $(R, R)$ and $(S, S)$ bridges on the molecule arrangement, molecular packing of 3-F-Cy, 3-F- $(S, S) C y$, and 3-F- $(R, R) C y$ single crystal structures are shown in Fig. 6 and S8-S15. $\dagger$ Like 3,5-Cl-Cy molecules, racemic 3-F-Cy molecules exhibit a tight $R / S$-chirality-induced tail-to-tail orientation packing with little intermolecular faceto-face $\pi-\pi$ interactions ( $d=3.54 \AA$, Fig. $6 \mathrm{a}, \mathrm{b}, \mathrm{S} 8$, and $\mathrm{S} 9 \dagger$ ). Many other strong intermolecular interactions including $\mathrm{H} \cdots \mathrm{H}$ (2.6159, 2.6679, 2.6804, 2.7083, 2.8033, 2.8395, 2.8640, 2.8837, and $2.9128 \AA), \mathrm{C} \cdots \mathrm{H}(2.7592,2.8238$, and $2.9546 \AA), \mathrm{O} \cdots \mathrm{H}$ (2.4532, 2.4701, 2.6238, 2.6691, 2.7395, and 2.8609 $\mathrm{A}$ ), and $\mathrm{F} \cdots \mathrm{H}$ (2.7008, 2.7167, 2.7771, 2.8422, and $2.8584 \AA$ ) interactions are found in the two adjacent 3-F-Cy molecules. The photophysical and AIE properties of 3-F-Cy, 3-F- $(\boldsymbol{S}, \boldsymbol{S}) \mathbf{C y}$, and 3-F- $(\boldsymbol{R}, \boldsymbol{R}) \mathbf{C y}$ are similar, but 3-F-Cy has a totally different molecule arrangement from 3-F- $(\boldsymbol{S}, \boldsymbol{S}) \mathbf{C y}$ and 3-F-(R,R)Cy (Fig. $6 \mathrm{~b}$ and c). The molecule arrangements of 3-F- $(\boldsymbol{S}, \boldsymbol{S}) \mathbf{C y}$ and $3-\mathbf{F}-(\boldsymbol{R}, \boldsymbol{R}) \mathbf{C y}$ are similar and mirrored. The two closest molecules in $3-\mathbf{F}-(S, S) \mathbf{C y}$ and $3-\mathbf{F}-(\boldsymbol{R}, \boldsymbol{R})$ Cy single crystals overlap to form a triplex tail-to-tail, head-totail, and head-to-tail arrangement. No intermolecular $\pi-\pi$ 
interactions but many similar strong intermolecular interac-

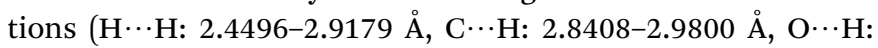
2.3803-2.8672 $\AA, \mathrm{H}_{\mathrm{Ar} \cdots \pi}: 2.54-2.57 \AA$, and $\mathrm{F} \cdots \mathrm{H}: 2.4464-$ $2.9903 \AA)$ are found in the two adjacent 3-F- $(\boldsymbol{S}, \boldsymbol{S}) \mathbf{C y}$ or 3-F- $(\boldsymbol{R}, \boldsymbol{R})$ Cy molecules (Fig. S10-S15 $)$ ). However, there is no intermolecular F $\cdots$ F interactions in 3-F-Cy, 3-F- $(S, S) C y$, and 3-F- $(\boldsymbol{R}, \boldsymbol{R}) \mathrm{Cy}$, which would be contributed to the fact that their $\Phi$ values (0.059-0.062) are lower than that of 3,5-Cl-Cy (0.32).

Our previous work demonstrated that the introduction of strong electron-accepting $-\mathrm{NO}_{2}$ substituents would be an efficient way to red shift fluorescence bands of non-conjugated AIEactive materials. ${ }^{14 g, 15}$ In this work, 3-NO${ }_{2}-\mathbf{C y}$ also shows a redshifted fluorescence band up to $565 \mathrm{~nm}$ (Fig. 4). We failed to grow good-quality single crystals for X-ray analysis in the previous and present work. It is fortunate that the X-ray single crystal structure of $3-\mathrm{NO}_{2}-(\boldsymbol{R}, \boldsymbol{R}) \mathbf{C y}$ is obtained in the literature. ${ }^{23}$ Unlike the above results, there are strong intermolecular faceto-face $\pi-\pi$ interactions in $3-\mathbf{N O}_{2}-(\boldsymbol{R}, \boldsymbol{R}) \mathbf{C y}(d=3.31 \AA$, Fig. S16 $\dagger$ ), according with the fact that of $\mathbf{3}-\mathrm{NO}_{2}-\mathbf{C y}$ has a redshifted fluorescence band with a not-so-high $\Phi$ value (0.051).

As shown in Fig. 7, two phenol rings and two benzene rings in 3-F-diPh and 3-Cl-diPh molecules are cis form rather than trans form, due to the existence of two chiral $(R, R)$ or $(S, S)$ carbon atoms. Two phenol rings and two benzene rings are separated each other to form their propeller structures, just like another well-known AIE-active material of TPE., ${ }^{\mathbf{9 1 3}, 20}$ Therefore, 3-F-diPh (2.4888-2.8510 ̊) and 3-Cl-diPh (2.3507-2.8279 $\mathrm{A})$ molecules can tightly packed without any face-to-face $\pi-\pi$ interactions in their single crystals (Fig. S17 and S18†). It should be noted that strong intermolecular $\mathrm{F} \cdots \mathrm{F}(3.2922 \AA)$ and $\mathrm{F} \cdots \mathrm{O}$ $(3.1760 \AA)$ interactions are found in 3-F-diPh and 3-Cl-diPh molecules, respectively. All these factors enable solid 3-F-diPh and 3-Cl-diPh have a high $\Phi$ value of 0.12 and 0.16 , respectively.

Having small $\pi$-conjugated systems, these pure organic salen ligands emit strong solid-state emission along with large Stokes shifts (up to $186 \mathrm{~nm}$ ). This would enable us to doubt that their emission originates from phosphorescence ${ }^{25}$ rather than fluorescence. Time-resolved emission decay spectra (Fig. S19 $\dagger$ ) reveal that the emission decay lifetime of 3-

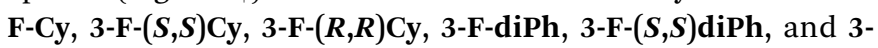
$\mathbf{F}-(\boldsymbol{R}, \boldsymbol{R})$ diph powders is $0.70,0.66,0.66,1.32,1.72$, and 0.93 $\mathrm{ns}$, respectively. These data are in the range of ns, indicating that their emission is not phosphorescence but fluorescence. The large Stokes shifts might be contributed to the intramolecular hydrogen bonds which would lead to keto and enol tautomers through an ultrafast excited state intramolecularproton transfer (ESIPT) process. ${ }^{26}$ With the same $R$ substituent, $\boldsymbol{R}$-Cy and $\boldsymbol{R}$-diPh have the similar fluorescence properties, because the low-energy transition is mainly be assigned to the $\pi \rightarrow \pi^{*}$ transition involving molecular orbitals essentially localized on the iminomethylphenol units with little contribution from the non-conjugated cyclohexane and 1,2-diphenylethane bridges (see the later discussion). Moreover, our previous work revealed that both the multi-Schiff base structure and $-\mathrm{OH}$ groups are of the greatest importance for AIE. ${ }^{\mathbf{1 4 g}}$

\section{Anion probe properties}

As shown in our previous work, ${ }^{15}$ TSBs (Fig. 1a) are tripod-like side-single-opening cages with three flexible arms of phenol ring and can be used as anion hosts through hydrogen bond. In this work, the two phenol rings of these salen ligands are cis form with a small dihedral angles, and thus they acting as clamps might react with anion through hydrogen bonds and detect anion consequently.

In general, $(S, S),(R, R)$, and racemic salen ligands have similar anion responses, and thus racemic salen ligands are discussed in this section. The anion probe properties of $\mathbf{C y}, \mathbf{3 - F}-$ Cy, 3-Cl-Cy, 3,5-Cl-Cy, diPh, 3-F-diPh, 3-Cl-diPh, and 3,5-Cl-diPh are demonstrated in Table S3, Fig. 8, and S20-S28. $\dagger$ As example, upon adding many anions, including $\mathrm{OH}^{-}, \mathrm{F}^{-}, \mathrm{Cl}^{-}, \mathrm{Br}^{-}, \mathrm{I}^{-}$, $\mathrm{NO}_{3}{ }^{-}, \mathrm{CO}_{3}{ }^{2-}, \mathrm{HCO}_{3}{ }^{-}, \mathrm{SO}_{4}{ }^{2-}, \mathrm{S}^{2-}, \mathrm{SO}_{3}{ }^{2-}, \mathrm{P}_{2} \mathrm{O}_{7}{ }^{4-}, \mathrm{PO}_{4}{ }^{3-}$, and $\mathrm{HPO}_{4}{ }^{2-}$, to dilute 3,5-Cl-diPh DMSO solution would turn on the blue fluorescence (up to 41.1-fold enhancement) of 3,5-Cl-diPh
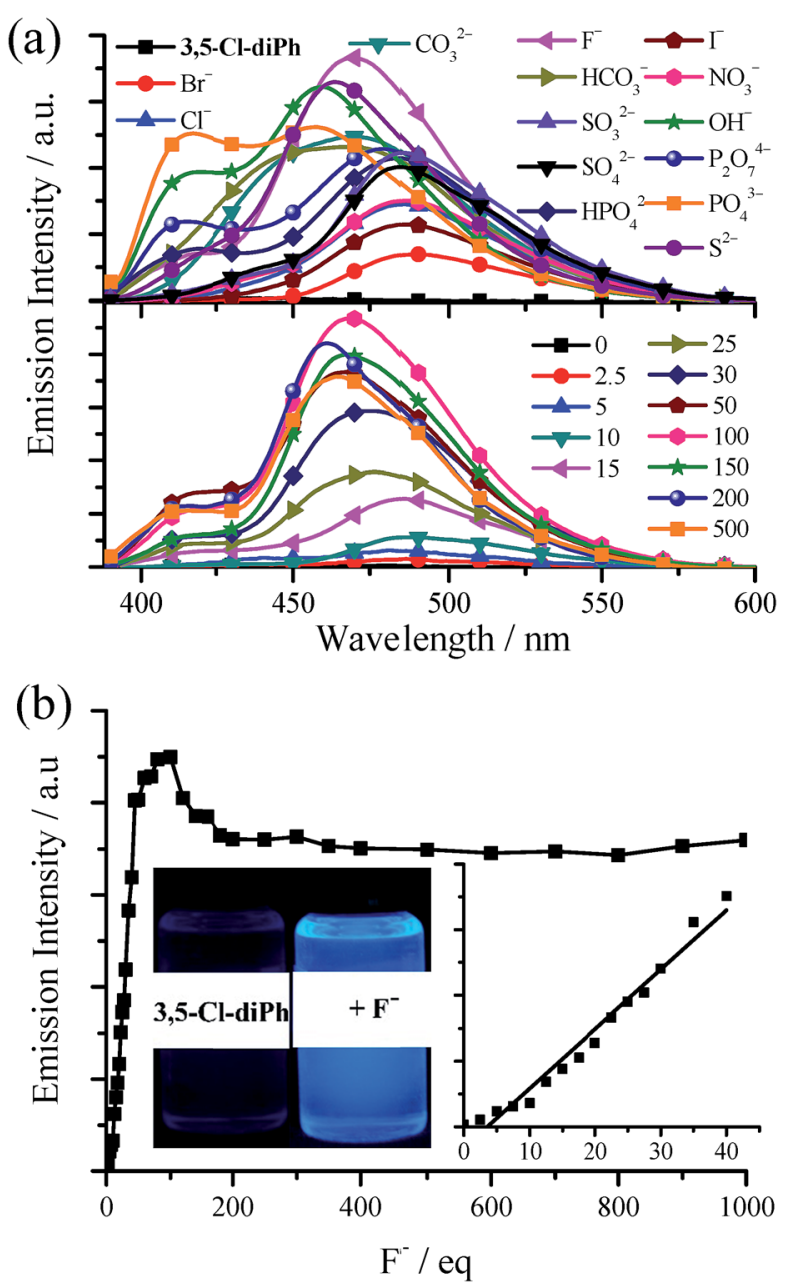

Fig. 8 (a) Top: emission spectra of 3,5-Cl-diPh upon the addition of 100 equivalent of different anions. Bottom: emission spectra of $3,5-\mathrm{Cl}-$ diPh upon the addition of different equivalent of $\mathrm{F}^{-}$. (b) Plot of emission intensity of 3,5-Cl-diPh at $468 \mathrm{~nm}$ ) as a function of $\mathrm{F}^{-}$concentration. Insert: photographs of $3,5-\mathrm{Cl}$-diPh, 3,5-Cl-diPh +100 equivalent of $\mathrm{F}^{-}$under $360 \mathrm{~nm}$ UV light). In all cases, the probe is $1.0 \times$ $10^{-5} \mathrm{~mol} \mathrm{dm}^{-3}$ in DMSO and is excited at $380 \mathrm{~nm}$. 
(Fig. 8a). Alkaline $\mathrm{OH}^{-}$(Fig. S20 and S21†) and neutral $\mathrm{F}^{-}$ (Fig. 8) were used to investigate the concentration effect. The fluorescence of $\mathbf{3 , 5}-\mathbf{C l}-\mathbf{d i P h}$ exhibits a linear enhancement (correlation coefficient $R^{2}=0.970, n=15$ ) upon the addition of 0-40 equivalent of $\mathrm{F}^{-}$and then reaches maximum upon the addition of 100 equivalent of $\mathrm{F}^{-}(\Phi=0.24)$. If adding $\mathrm{F}^{-}$further, the fluorescence would reduce and finally reach saturation $(\Phi=$ 0.21). A similar fluorescence enhancement is observed upon adding $\mathrm{OH}^{-}$to dilute 3,5-Cl-diPh solution ( $\Phi$ up to 0.29 ). The probe performance would be much worse if other solvents, such as $\mathrm{MeCN}, \mathrm{EtOH}$, and $\mathrm{MeOH}$, are used. ${ }^{\mathbf{1 5}}$

Cy, 3-F-Cy, 3-Cl-Cy, 3,5-Cl-Cy, diPh, 3-F-diPh, and 3-Cl-diPh have similar anion effects with 3,5-Cl-diPh that they are very sensitive to $\mathrm{F}^{-}, \mathrm{OH}^{-}, \mathrm{S}^{2-}$ and $\mathrm{PO}_{4}{ }^{3-}$ (Table $\mathrm{S} 3 \dagger$ ). On the contrary, step-like $\mathrm{C}_{4}$ (ref. 15) and $\mathrm{C}_{2}$ have much less anion effect on fluorescence (Fig. $\mathrm{S} 29 \dagger$ ). Our previous work ${ }^{\mathbf{1 5}}$ revealed that the reaction between TSBs and $\mathrm{X}^{-}$is not a normal chemical reaction but intermolecular hydrogen bonding $\left(-\mathrm{O}-\mathrm{H} \cdots \mathrm{X}^{-}\right)$. The two phenol rings of Cy, 3-F-Cy, 3,5-Cl-Cy, 3-F-diPh, and 3-Cldiph are cis and diagonal form with a small dihedral angle of $56.6,51.5,53.8,54.6$, and $47.5^{\circ}$, respectively. The intramolecular distance $\mathrm{O} \cdots \mathrm{O}$ of $\mathbf{C y}, \mathbf{3 - F}-\mathrm{Cy}, \mathbf{3 , 5}-\mathbf{C l}-\mathrm{Cy}, \mathbf{3 - F - d i P h}$, and 3-Cl-diPh is 6.081, 6.494, 6.352, 5.342, and $5.602 \AA$, respectively. However, $\mathrm{C}_{4}$ and $\mathrm{C}_{2}$ are step-like and their two phenol rings are parallelly separated with much longer intramolecular distance $\mathrm{O} \cdots \mathrm{O}$ of 8.314 and $10.52 \AA$ A, respectively. ${ }^{14 g}$ It means that, like TSBs ${ }^{15} \mathbf{C y}$, 3-F-Cy, 3,5-Cl-Cy, 3-F-diPh, and 3-Cl-diPh are easier to act as tetradentate chelating agents (see the later discussion) and consequently react with an anion more tightly than $\mathrm{C}_{4}$ and $\mathrm{C}_{2}$ (Fig. S30†).

\section{Chirality and chiral recognition}

The chirality properties of 3-F-Cy, 3-F- $(S, S) C y, 3-F-(R, R) C y, 3-F-$ diPh, 3-F-( $\boldsymbol{S}, \boldsymbol{S}) \mathrm{diPh}$, and 3-F-( $\boldsymbol{R}, \boldsymbol{R}) \mathrm{diPh}$ are examined by circular dichroism (CD) spectra. As depicted in Fig. 9, 3-F-(S,S)diPh shows a positive cotton effect at $326 \mathrm{~nm}$ and further strong peaks at 270 , and $249 \mathrm{~nm}$. The CD spectrum of $\mathbf{3 - F}-(\boldsymbol{R}, \boldsymbol{R}) \mathbf{d i P h}$

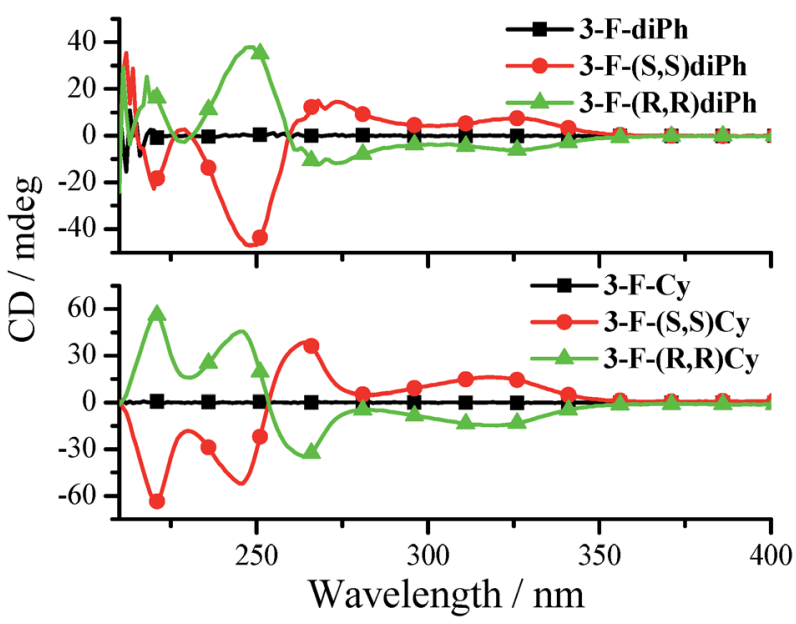

Fig. 9 CD spectra of 3-F-Cy, 3-F- $(R, R) C y, 3-F-(S, S) C y, 3-F-d i P h, 3-F-$ $(R, R)$ diPh, and 3-F- $(S, S)$ diPh in $\mathrm{MeCN}\left(3.0 \times 10^{-5} \mathrm{~mol} \mathrm{dm}^{-3}\right)$. exactly mirrors that of $\mathbf{3}-\mathbf{F}-(\boldsymbol{S}, \boldsymbol{S}) \mathbf{d i P h}$, indicating that the two compounds are a pair of enantiomers. Moreover, racemic 3-Fdiph has little CD signals. Similar phenomena are observed for 3-F-Cy, 3-F- $(S, S) \mathrm{Cy}$, and 3-F- $(\boldsymbol{R}, \boldsymbol{R}) \mathrm{Cy}$ as well. Moreover, 3-F- $(S, S)$ Cy and 3-F-(S,S)diPh (or 3-F- $(\boldsymbol{R}, \boldsymbol{R}) \mathrm{Cy}$ and $3-\mathrm{F}-(\boldsymbol{R}, \boldsymbol{R}) \mathrm{diPh}$ ) exhibit similar CD spectra, revealing that they have the same chiral configuration and energy transition.

The fluorescence responses towards various $\mathrm{L}^{-}$or $\mathrm{D}$-amino acids were investigated under the similar experimental conditions with anion detection (Tables S4-S10, Fig. 10, and S31$\mathrm{S} 63 \dagger)$. Considering the problem of solubility in both water and DMSO, we chose ten amino acids including alanine (Ala), valine (Val), leucine (Leu), serine (Ser), proline (Pro), histidine (His), tryptophan (Trp), arginine (Arg), glutamate (Glu), and glutamine (Gln). Upon adding amino acids, the fluorescence enhancements of $\mathbf{C y}$ and diPh (Table S4 and Fig. S31†) are lower than those of 3-F-Cy (Table S5 and Fig. S32-S37†), 3-Cl-Cy (Table S6 and Fig. S38-S43†), 3,5-Cl-Cy (Table S7 and Fig. S44-S49†), 3-F-diPh (Table S8 and Fig. S50-S55†), 3-Cl-diPh (Table S9 and Fig. S56-S61 $\dagger$ ), and 3,5-Cl-diPh (Table S10, Fig. 10, S62, and S63 $\dagger$ ). Since all nature amino acids are L-type ones, firstly we used 3,5-Cl-(S,S)diPh and 3,5-Cl-(R,R)diPh to probe different L-amino acids. As shown in Fig. 10a and Table S10, $\dagger$ like adding anion, adding different $\mathrm{L}$-amino acids to 3,5-Cl- $(\boldsymbol{S}, \boldsymbol{S}) \mathrm{diPh}$ or 3,5 Cl- $(\boldsymbol{R}, \boldsymbol{R}) \mathbf{d i P h}$ DMSO solutions would turn on their fluorescence ( $\Phi$ up to 0.26 ), indicating that they might be used as universal amino acid probes (Fig. 10c, S62, and S63†). On the whole, 3,5Cl- $(S, S)$ diPh and 3,5-Cl- $(R, R)$ diPh have a similar response that $\mathrm{L}^{-}$ Arg, L-Pro, and L-Ala would induce stronger fluorescence enhancements than other amino acids. Moreover, chiral 3,5-Cl$(\boldsymbol{S}, \boldsymbol{S}) \mathrm{diPh}$ and $\mathbf{3 , 5}-\mathbf{C l}-(\boldsymbol{R}, \boldsymbol{R}) \mathrm{diPh}$ could also discriminate the enantiomers of some amino acids (Fig. $10 \mathrm{~b}$ and Table S10 $\dagger$ ). For example, adding $\mathrm{D}^{-}$or $\mathrm{L}-\mathrm{Gln}$ to $3,5-\mathrm{Cl}-(\boldsymbol{S}, \boldsymbol{S})$ diPh solution, the fluorescence of 3,5-Cl-(S,S)diPh would turn on with a $36.2-$ and 5.82 -fold enhancement, respectively. The selective recognition of chiral molecular enantiomers is related to the enantiomeric fluorescence difference ratio, ef, according to ef $=\left(I_{\mathrm{D}}-I_{0}\right) /\left(I_{\mathrm{L}}-\right.$ $I_{0}$ ), in which $I_{0}$ represents the fluorescence emission intensity of receptor in the absence of a chiral substrate and $I_{\mathrm{D}}$ and $I_{\mathrm{L}}$ are the fluorescence intensities in the presence of $\mathrm{D}$ - and L-substrates, respectively. 3,5-Cl-(S,S)diPh shows an good ef value of 6.22 for enantioselective recognition of $\mathrm{D}^{-}$and $\mathrm{L}-\mathrm{Gln}$. For other amino acids, His ( $\mathrm{ef}=2.71)$, Arg ( $\mathrm{ef}=2.27)$, and $\operatorname{Trp}(\mathrm{ef}=$ 2.13) enantiomers could be discriminated by the $\mathbf{3 , 5}-\mathbf{C l}-(\boldsymbol{S}, \boldsymbol{S})$ diPh. 3,5-Cl- $(\boldsymbol{R}, \boldsymbol{R}) \mathbf{d i P h}$ can identify $\mathrm{Gln}(\mathrm{ef}=2.93)$ and His $(\mathrm{ef}=$ 2.46) enantiomers.

In addition, $3-\mathbf{F}-(\boldsymbol{S}, \boldsymbol{S}) \mathrm{diPh}$ has an excellent ef value of 0.11 for enantioselective recognition of $\mathrm{D}^{-}$and $\mathrm{L}^{-}$Val (Table S8 and Fig. S54†). 3-F- $(\boldsymbol{R}, \boldsymbol{R})$ diPh can discriminate $\mathrm{D}^{-}$and $\mathrm{L}$-Arg (ef $=$ 4.89) (Table S9†). 3-Cl-(S,S)diPh can efficiently discriminate Arg (ef $=5.48)$ and $\mathrm{Gln}(\mathrm{ef}=0.21)$ enantiomers, on the other hand, Arg (ef $=4.43)$ and Trp (ef $=0.18)$ enantiomers can be can be distinguished by 3-Cl-(R,R)diPh (Table S9†). 3-F-Cy (Table S5 $\dagger$ ), 3-Cl-Cy (Table S6 $\dagger$ ), and 3,5-Cl-Cy (Table S7†) generally exhibit worse ef values than 3-F-diPh (Table S8 $\dagger$ ), 3-Cl-diPh (Table S9†), and 3,5-Cl-diPh (Table S10 $\dagger$ ). However, since it is too difficult to grow good-quality single crystals from the mixture of the dye 

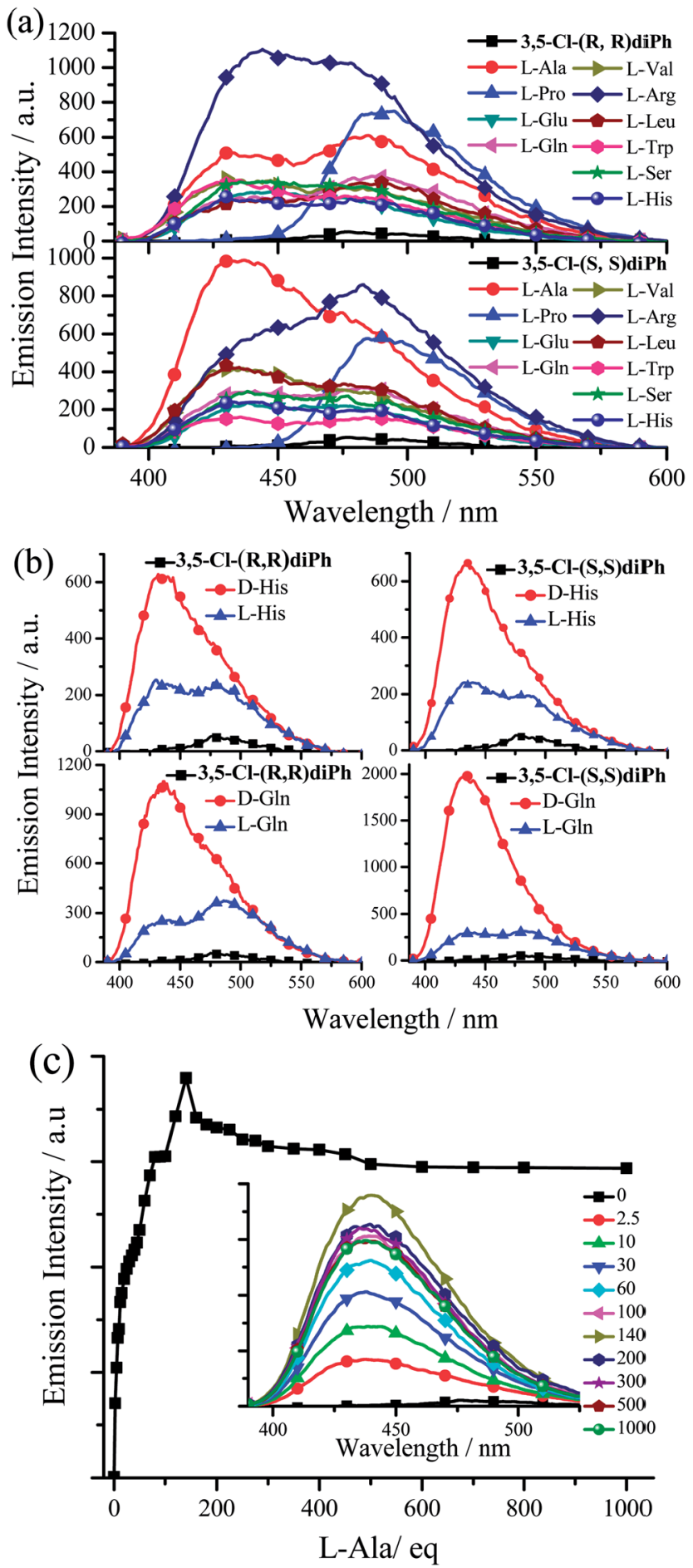

Fig. 10 (a) Emission spectra of 3,5-Cl-(S,S)diPh and 3,5-Cl- $(R, R)$ diPh upon the addition of 100 equivalent of different L-amino acids. (b) Emission spectra of 3,5-Cl-(S,S)diPh and 3,5-Cl- $(R, R)$ diPh upon the addition of 100 equivalent of different $L$-and $D$-amino acids. (c) Plot of emission intensity of $3,5-\mathrm{Cl}-(R, R)$ diPh at $440 \mathrm{~nm}$ as a function of L-Arg concentration. Insert: emission spectra of $3,5-\mathrm{Cl}-(R, R)$ diPh upon the addition of different equivalent of L-Arg. In all cases, the probe is $1.0 \times 10^{-5} \mathrm{~mol} \mathrm{dm}^{-3}$ in DMSO and is excited at $380 \mathrm{~nm}$.

and amino acid in DMSO solution, we failed to get a clear insight into the chiral discrimination ability (see the later discussion). We just guess that diPhs have a 1,2-diphenylethane bridge but not a circular bridge of cyclohexane, hence, compared with Cys, they would be more flexible and consequently might have a better ability to form a cavity ${ }^{4 a}$ for the recognition of a tiny chiral structure difference between $\mathrm{D}$ - and L-amino acid.

\section{Mechanism of anion and amino acid probes}

In order to investigate the possible interaction mechanism between the dye and anion/amino acid, ${ }^{1} \mathrm{H}$ nuclear magnetic resonance $\left({ }^{1} \mathrm{H}\right.$ NMR) analysis was done. As shown in Fig. 11a, the ${ }^{1} \mathrm{H}$ NMR signal of $\mathrm{H}^{1}$ atoms in 3,5-Cl-diph appears a small broad peak at downfield ( $\delta=14.5 \mathrm{ppm})$ due to the existence of the intramolecular hydrogen bonds $(-\mathrm{OH} \cdots \mathrm{N}$, Fig. 5$) .^{15,27}$ If adding 100 equivalent of $\mathrm{OH}^{-}$(Fig. 11b), $\mathrm{F}^{-}$(Fig. 11c), or L-Arg (Fig. 11d) (in $\mathrm{D}_{2} \mathrm{O}$ ), this downfield peak would disappear and reform a new small sharp peak at upfield $(\delta=10.1-10.2 \mathrm{ppm})$, which might be assigned to the ArOH without intramolecular hydrogen bonds. ${ }^{27,28}$ This upfield shift indicates that the strong intramolecular hydrogen bonds are destroyed by adding anion/ amino acid. At the same time, the reduction (about 1/2-2/3) of peak area in new peak reveals the formation of new intermolecular hydrogen bonds. These intermolecular hydrogen bonds would increase the molecular electron density through-bond effect and lead to upfield shifts of other $\mathrm{H}$ atoms consequently. ${ }^{29}$ Moreover, the ${ }^{1} \mathrm{H}$ NMR signal of $\mathrm{H}^{3}$ at chiral carbon atoms also shows an obvious upfield shift from $\delta=5.2 \mathrm{ppm}$ into $\delta=4.7,\left(5.0\right.$ and 4.2), and $3.9 \mathrm{ppm}$ upon adding $\mathrm{OH}^{-}, \mathrm{F}^{-}$, and L-Arg, respectively, which might indicate that the neighboring nitrogen atoms have strong intermolecular interactions with anion and amino acid through hydrogen and halogen bonds.

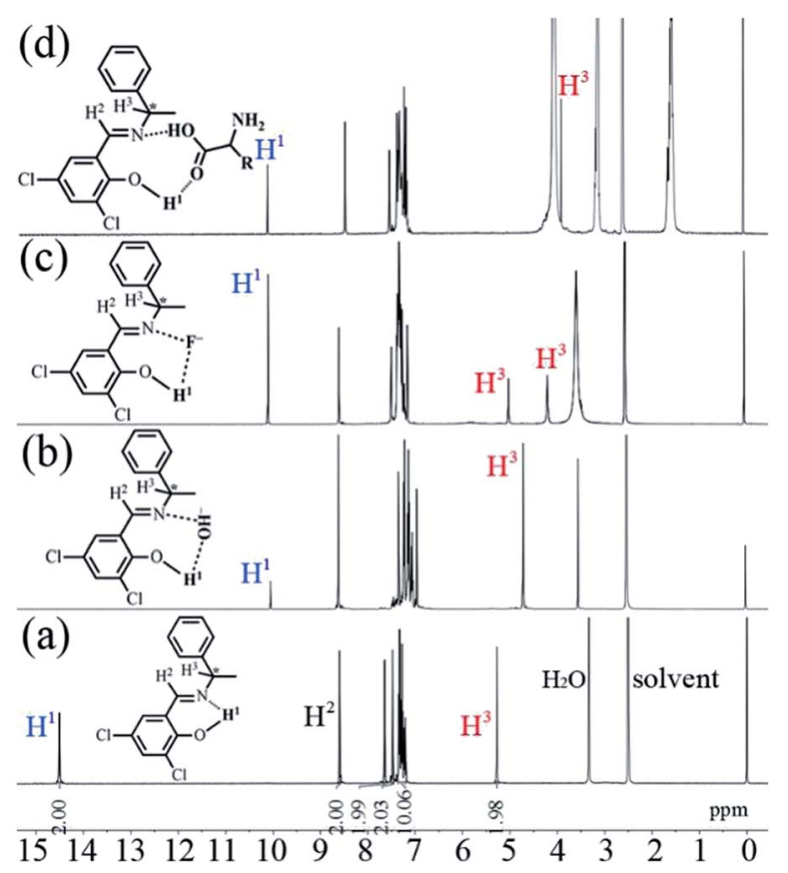

Fig. $11{ }^{1} \mathrm{H}$ NMR spectra of 3,5-Cl-diPh (a), 3,5-Cl-diPh +100 equivalent of $\mathrm{OH}^{-}$(b), 3,5-Cl-diPh +100 equivalent of $\mathrm{F}^{-}$(c), and 3,5-Cl$(R, R)$ diPh +100 equivalent of $\mathrm{L}-\mathrm{Arg}(\mathrm{d})$ in $\mathrm{DMSO}-\mathrm{d}_{6}$. 
Furthermore, the blank experiments (Fig. S64 and S65†) revealed that the ${ }^{1} \mathrm{H}$ NMR peak at 10.1-10.2 was not caused by an impurity.

The mechanisms of the aggregation- and anion/amino acidinduced fluorescence enhancement are totally different. For example, the green AIE of 3-F-Cy is originated from the aggregated state (in water or solid) but its blue anion/amino acidinduced fluorescence is originated from the monomer $(1.0 \times$ $10^{-5} \mathrm{~mol} \mathrm{dm}^{-3}$ in DMSO). To gain insight into the nature of the excited states and transitions, gas-phase density functional theory (DFT) and time-dependent-DFT (TD-DFT) were also carried out for 3-F-Cy with the Gaussian 09 program package (B3LYP 6-31G(d,p)). The energy absorption bands of 3-F-Cy $\left(\lambda_{\mathrm{abs}}=316,253\right.$, and $211 \mathrm{~nm}$ in MeCN) are reproduced well by the computation, which predict three absorption peaks at 318 , 248, and $213 \mathrm{~nm}$ (Fig. 12). The lower energy absorption is mainly contributed to the highest occupied molecular orbital (HOMO) $\rightarrow$ lowest unoccupied molecular orbital (LUMO) (318 nm, oscillator strength, $\left.f_{\text {osc }}=0.0814\right)$. The energy level and orbital isosurfaces diagrams of 3-F-Cy (Fig. 12) reveal that its HOMO and LUMO are mainly made up of the $\pi$-functions of iminomethylphenol units rather than the cyclohexane bridge. Therefore, the lower energy absorption can mainly be assigned to the $\pi \rightarrow \pi^{*}$ transition involving molecular orbitals essentially localized on the iminomethylphenol units with little contribution from the non-conjugated cyclohexane bridge. As mentioned above, $\mathrm{F}^{-}, \mathrm{OH}^{-}$, or $\mathrm{L}-\mathrm{Arg}$ would lead to changing $-\mathrm{OH}$ into $\mathrm{O}^{-}$, and thus 3-F-Cy in form of $\mathrm{O}^{-}$is used to evaluate the nature of the anion/amino acid-induced excited states and transitions by calculation. For optimized structure, 3-F-Cy (in form of $\mathrm{O}^{-}$, Fig. 12) has a much bigger dihedral angle $\left(79.0^{\circ}\right)$ between two phenol rings than 3-F-Cy (in form of $\mathrm{OH}, 51.5^{\circ}$ ). The lower energy absorption band of 3-F-Cy (in form of $\mathrm{O}^{-}$, $\lambda_{\mathrm{abs}}=365$ and $350 \mathrm{~nm}$ for experiment and computation, respectively) are mainly composed of three transitions, including HOMO $\rightarrow$ LUMO $\left(360 \mathrm{~nm}, f_{\text {osc }}=0.150\right)$, HOMO $-1 \rightarrow$ LUMO+1 $\left(344 \mathrm{~nm}, f_{\text {osc }}=0.175\right)$, and HOMO $\rightarrow$ LUMO +1

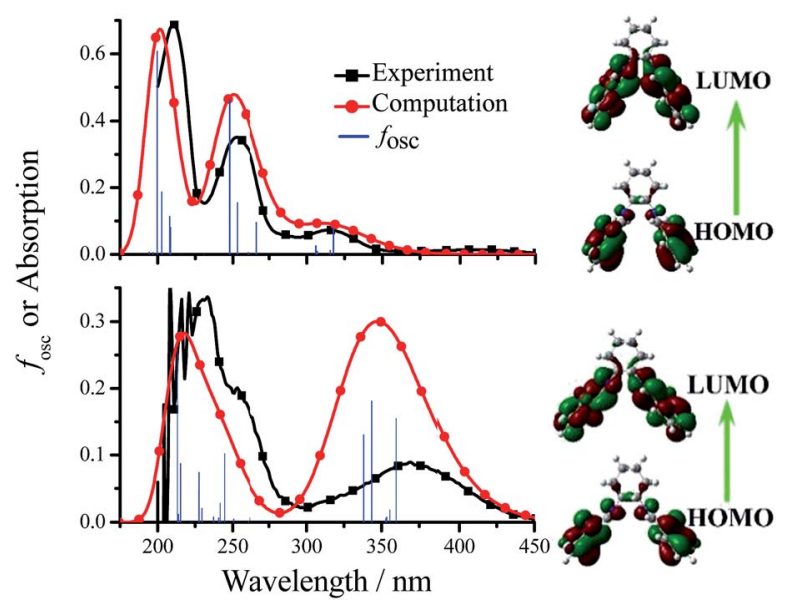

Fig. 12 Computational (gas-phase) and experimental absorption spectra and Frontier molecular orbitals of 3-F-Cy (top, in form of $\mathrm{OH}$ ) and 3-F-Cy +100 equivalent of $\mathrm{OH}^{-}$(bottom, in form of $\mathrm{O}^{-}$) $\mathrm{MeCN}$ solution.

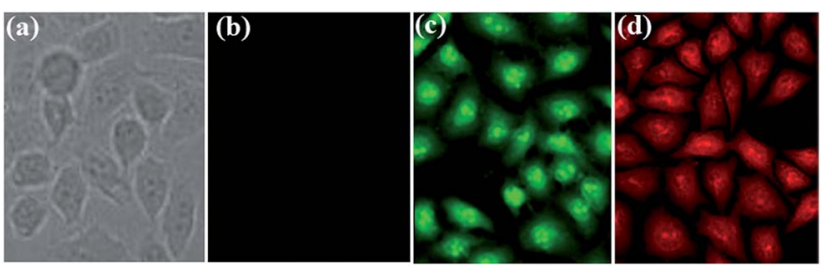

Fig. 13 Brightfield (a) incubated without dye and fluorescence images (b) incubated without dye; (c) incubated with 3,5-Cl-Cy; (d) incubated with 3- $\mathrm{NO}_{2}-\mathrm{Cy}$ of HeLa cells.

(338 nm, $f_{\text {osc }}=0.127$ ). The $\pi$-functions of HOMO, HOMO-1, LUMO and LUMO+1 of 3-F-Cy in form of $\mathrm{OH}$ and $\mathrm{O}^{-}$are similar, which reveals that anion/amino acid would not induce to change of the way of transition ( $\pi \rightarrow \pi^{*}$ transition). This is much different from our previous work ${ }^{15}$ that anion would induce to change of the way of transition from $n \rightarrow \pi^{*}$ into $\pi \rightarrow$ $\pi^{*}$ for TSBs. Moreover, anion/amino acid would red shift the lower energy absorption band with an increment of molar extinction co-efficient (Fig. 12 and S66†). This phenomenon can be reasonably explained by the fact that electron-rich $\mathrm{ArO}^{-}$ anions have resonance structures of benzoquinone. ${ }^{28}$ These resonance structures lead the $\pi$-function Frontier molecular orbitals to a uniform distribution in the molecule skeleton, and consequently 3-F-Cy (in form of $\mathrm{O}^{-}$) has not only a smaller energy gap of transition but also an increment of molar extinction co-efficient and oscillator strength. This also might be contributed to its high fluorescence quantum yield in dilute DMSO solution. It is strange that dilute 3-F-Cy (in form of $\mathrm{O}^{-}$) DMSO solution having a red-shifted absorption spectrum shows a blue-shifted fluorescence spectrum, but AIE of 3-F-Cy (in form of $\mathrm{OH}$, in solid or water) is green-yellow. There is no anymore ESIPT for 3-F-Cy (in form of $\mathrm{O}^{-}$), which might be contributed to its blue fluorescence.

\section{Living cell imaging}

These non-conjugated AIE-active materials might have a lower cytotoxicity and better biocompatibility, and thus green-lightemitting 3,5-Cl-Cy and red-light-emitting 3- $\mathrm{NO}_{2}-\mathrm{Cy}$ were used in cell imaging applications. The HeLa cells were imaged by the dye using a standard cell-staining protocol. As can be seen from Fig. 13, incubated with 3,5-Cl-Cy or 3-NO ${ }_{2}$-Cy, the HeLa cells grow similar as in the control experiments in the absence of the dyes, indicating that both dyes have little toxicity on the living cells. HeLa cells show negligible background fluorescence. However, intense intracellular green and red AIE is observed after HeLa cells are incubated with 3,5-Cl-Cy or $3-\mathbf{N O}_{2}-\mathbf{C y}$, respectively. Therefore, these AIE-active materials may have potentially applications in probing or monitoring biologically important processes in vitro as well as in vivo.

\section{Conclusion}

In the present work, we demonstrate the unique AIE, chirality, anion/amino acid probe, and cell imaging properties a series of non-conjugated and cyclohexane/1,2-diphenylethane-linked 
salen ligands. These V- or propeller-type salen ligands with small $\pi$-conjugated systems emit strong blue, green, and red AIE through little $\pi-\pi$ interactions and strong non-covalent intermolecular interactions, such as $\mathrm{O} \cdots \mathrm{H}, \mathrm{H} \cdots \mathrm{H}, \mathrm{C} \cdots \mathrm{H}, \mathrm{F} \cdots$ $\mathrm{H}, \mathrm{F} \cdots \mathrm{F}, \mathrm{Cl} \cdots \mathrm{H}, \mathrm{Cl} \cdots \mathrm{O}$, and $\mathrm{Cl} \cdots \mathrm{Cl}$. Moreover, combine with the advantages of non-conjugation and chirality, these soft materials have multiple and strong interactions with anions and amino acids by hydrogen and halogen bonds, and thus they might be used as universal anion probes and chiral receptors of unprotected amino acids with a good enantiomeric selectivity. Therefore, we believe that these simple salen ligands provide a new paradigm in the design of chiral and non-conjugated fluorescent materials for developing advanced organic optoelectronic devices, florescent bio-probes, and cell imaging, and so on. Further studies on circularly polarized luminescence ${ }^{30}$ of these salen ligands are currently underway in our laboratory.

\section{Conflicts of interest}

There are no conflicts to declare.

\section{Acknowledgements}

This work was supported by the National Natural Science Foundation of China (no. 21372169). We acknowledge the comprehensive training platform of the specialized laboratory of the College of Chemistry, Sichuan University, for material analysis.

\section{Notes and references}

1 (a) H. C. Aspinall, Chem. Rev., 2002, 102, 1807; (b) J. Crassous, Chem. Soc. Rev., 2009, 38, 830; (c) M. Liu, L. Zhang and T. Wang, Chem. Rev., 2015, 115, 7304.

2 (a) L. Pu, Chem. Rev., 2004, 104, 1687; (b) G. A. Hembury, V. V. Borovkov and Y. Inoue, Chem. Rev., 2008, 108, 1; (c) A. Zehnacker and M. A. Suhm, Angew. Chem., Int. Ed., 2008, 47, 6970; (d) A. Accetta, R. Corradini and R. Marchelli, Top. Curr. Chem., 2011, 300, 175; (e) L. Pu, Acc. Chem. Res., 2012, 45, 150; $(f)$ D. Leung, S. O. Kang and E. V. Anslyn, Chem. Soc. Rev., 2012, 41, 448; (g) X. Zhang, J. Yin and J. Yoon, Chem. Rev., 2014, 114, 4918; (h) L. You, D. Zha and E. V. Anslyn, Chem. Rev., 2015, 115, 7840.

3 (a) X. Yang, X. Liu, K. Shen, C. Zhu and Y. Cheng, Org. Lett., 2011, 13, 3510; (b) F. Li, L. Li, W. Yang, L. S. Zheng, Z. J. Zheng, K. Jiang, Y. Lu and L. W. Xu, Tetrahedron Lett., 2013, 54, 1584; (c) Z. Huang, S. Yu, K. Wen, X. Yu and L. Pu, Chem. Sci., 2014, 5, 3457.

4 (a) H. T. Feng, X. Zhang and Y. S. Zheng, J. Org. Chem., 2015, 80, 8096; (b) J. B. Xiong, W. Z. Xie, J. P. Sun, J. H. Wang, Z. H. Zhu, H. T. Feng, D. Guo, H. Zhang and Y. S. Zheng, J. Org. Chem., 2016, 81, 3720.

5 (a) H. L. Liu, H. P. Zhu, X. L. Hou and L. Pu, Org. Lett., 2010, 12, 4172; (b) H. Jintoku, M. Takafuji, R. Odac and H. Ihara, Chem. Commun., 2012, 48, 4881; (c) T. Liu, Y. Su, H. Song and Y. Lv, Analyst, 2013, 138, 6558; (d) B. Aswathy and G. Sony, J. Lumin., 2014, 154, 541.
6 (a) U. Mitschke and P. Bauerle, J. Mater. Chem., 2000, 10, 1471; (b) L. S. Hung and C. H. Chen, Mater. Sci. Eng., A, 2002, 39, 143; (c) J. D. Slinker, J. Rivnay, J. S. Moskowitz, J. B. Parker, S. Bernhard, H. D. Abruoac and G. Malliaras, J. Mater. Chem., 2007, 17, 2976; (d) Q. Zhao, C. H. Huang and F. Y. Li, Chem. Soc. Rev., 2011, 40, 2508; (e) J. F. Zhang, Y. Zhou, J. Yoon and J. S. Kim, Chem. Soc. Rev., 2011, 40, 3416; (f) Y. Feng, J. H. Cheng, L. Zhou, X. G. Zhou and H. F. Xiang, Analyst, 2012, 137, 4885; $(g)$ H. F. Xiang, J. H. Cheng, X. F. Ma, X. G. Zhou and J. J. Chruma, Chem. Soc. Rev., 2013, 42, 6128; (h) Y. M. Yang, Q. Zhao, W. Feng and F. Y. Li, Chem. Rev., 2013, 113, 192; (i) J. H. Cheng, X. G. Zhou and H. F. Xiang, Analyst, 2015, 140, 7082; (j) J. Liang, B. Z. Tang and B. Liu, Chem. Soc. Rev., 2015, 44, 2798.

7 (a) J. B. Birks, Photophysics of Aromatic Molecules, Wiley, New York, 1970; (b) X. F. Ma, R. Sun, J. H. Cheng, J. Y. Liu, F. Gou, H. F. Xiang and X. G. Zhou, J. Chem. Educ., 2016, 93, 345.

8 B. Z. Tang, New Structural Motifs for Solid Light Emitters, Cutting-Edge Chemistry, ACS, 2016, https://www.acs.org/ content/acs/en/pressroom/cutting-edge-chemistry/newstructural-motifs-for-solid-light-emitters.html? cid=home_promo.

9 Y. Hong, J. W. Y. Lam and B. Z. Tang, Chem. Soc. Rev., 2011, 40, 5361.

10 C. M. Xing, J. W. Y. Lam, A. Qin, Y. Dong, M. Haussler, W. T. Yang and B. Z. Tang, Polym. Mater. Sci. Eng., 2007, 96, 418.

11 A. Pucci, R. Rausa and F. Ciardelli, Macromol. Chem. Phys., 2008, 209, 900.

12 M. S. Mathew, K. Sreenivasan and K. Joseph, RSC Adv., 2015, 5, 100176.

13 (a) J. Luo, Z. Xie, J. W. Y. Lam, L. Cheng, H. Chen, C. Qiu, H. S. Kwok, X. Zhan, Y. Liu, D. Zhu and B. Z. Tang, Chem. Commun., 2001, 1740; (b) J. Mei, N. L. C. Leung, R. T. K. Kwok, J. W. Y. Lam and B. Z. Tang, Chem. Rev., 2015, 115, 11718.

14 (a) L. Zhou, P. Y. Cai, Y. Feng, J. H. Cheng, H. F. Xiang, J. Liu, D. Wu and X. G. Zhou, Anal. Chim. Acta, 2012, 735, 96; (b) L. Zhou, Y. Feng, J. H. Cheng, N. Sun, X. G. Zhou and H. F. Xiang, $R S C A d v$., 2012, 2, 10529; (c) J. H. Cheng, K. Y. Wei, X. F. Ma, X. G. Zhou and H. F. Xiang, J. Phys. Chem. C, 2013, 117, 16552; (d) J. H. Cheng, Y. H. Zhang, X. F. Ma, X. G. Zhou and H. F. Xiang, Chem. Commun., 2013, 49, 11791; (e) J. H. Cheng, X. F. Ma, Y. H. Zhang, J. Y. Liu, X. G. Zhou and H. F. Xiang, Inorg. Chem., 2014, 53, 3210; (f) X. F. Ma, J. H. Cheng, J. Y. Liu, X. G. Zhou and H. F. Xiang, New J. Chem., 2015, 39, 492; (g) J. H. Cheng, Y. X. Li, R. Sun, J. Y. Liu, F. Gou, X. G. Zhou, H. F. Xiang and J. Liu, J. Mater. Chem. C, 2015, 3, 11099.

15 X. H. Zhang, G. Y. Shen, F. Gou, J. H. Cheng, X. G. Zhou and H. F. Xiang, Mater. Chem. Front., 2017, 1, 1041.

16 (a) L. Canali and D. C. Sherrington, Chem. Soc. Rev., 1999, 28, 85; (b) P. G. Cozzi, Chem. Soc. Rev., 2004, 33, 410; (c) C. Baleizao and H. Garcia, Chem. Rev., 2006, 106, 3987.

17 P. S. Hariharan and S. P. Anthony, Spectrochim. Acta, Part A, 2015, 136, 1658. 
18 J. N. Demas and G. A. Crosby, J. Phys. Chem., 1971, 75, 991. 19 (a) Y. Liu, Y. Tang, N. N. Barashkov, I. S. Irgibaeva, J. W. Y. Lam, R. Hu, D. Birimzhanova, Y. Yu and B. Z. Tang, J. Am. Chem. Soc., 2010, 132, 13951; (b) Y. Yuan, R. T. K. Kwok, B. Z. Tang and B. Liu, J. Am. Chem. Soc., 2014, 136, 2546.

20 (a) J. Yang, L. Li, Y. Yu, Z. C. Ren, Q. Peng, S. H. Ye, Q. Q. Li and Z. Li, Mater. Chem. Front., 2017, 1, 91; (b) C. W. T. Leung, Y. Hong, S. Chen, E. Zhao, J. W. Y. Lam and B. Z. Tang, J. Am. Chem. Soc., 2013, 135, 62; (c) S. Chen, Y. Hong, Y. Liu, J. Liu, C. W. T. Leung, M. Li, R. T. K. Kwok, E. Zhao, J. W. Y. Lam, Y. Yu and B. Z. Tang, J. Am. Chem. Soc., 2013, 135, 4926; (d) L. Chen, G. W. Lin, H. R. Peng, S. Y. Ding, W. W. Luo, R. R. Hu, S. M. Chen, F. Huang, A. J. Qin, Z. J. Zhao and B. Z. Tang, Mater. Chem. Front., 2017, 1, 176; (e) J. Yang, J. Huang, Q. Q. Li and Z. Li, J. Mater. Chem. C, 2016, 4, 2663.

21 J. C. Cannadine, J. P. Corden, W. Errington, P. Moore and M. G. H. Wallbridge, Acta Crystallogr., Sect. C: Cryst. Struct. Commun., 1996, 52, 1014.

22 E. Hadjoudis, A. Rontoyianni, K. Ambroziak, T. Dziembowska and I. M. Mavridis, J. Photochem. Photobiol., A, 2004, 162, 521.
23 E. Rafii, M. Giorgi, N. Vanthuyne and C. Roussel, ARKIVOC, 2005, 10, 86.

24 (a) P. Metrangolo, H. Neukirch, T. Pilati and G. Resnati, Acc. Chem. Res., 2005, 38, 386; (b) G. Cavallo, P. Metrangolo, T. Pilati, G. Resnati, M. Sansotera and G. Terraneo, Chem. Soc. Rev., 2010, 39, 3772.

25 S. Mukherjee and P. Thilagar, Chem. Commun., 2015, 51, 10988.

26 V. S. Padalkar and S. Seki, Chem. Soc. Rev., 2016, 45, 169.

27 J. H. Cheng, F. Gou, X. H. Zhang, G. Y. Shen, X. G. Zhou and H. F. Xiang, Inorg. Chem., 2016, 55, 9221.

28 J. Y. Liu, J. H. Cheng, X. F. Ma, X. G. Zhou and H. F. Xiang, Res. Chem. Intermed., 2016, 42, 5027.

29 (a) M. Boiocchi, L. Del Boca, D. E. Gomez, L. Fabbrizzi, M. Licchelli and E. Monzani, J. Am. Chem. Soc., 2004, 126, 16507; (b) Q. Li, Y. Guo, J. Xu and S. J. Shao, Sens. Actuators, B, 2011, 158, 427.

30 (a) E. M. Sanchez-Carnerero, A. R. Agarrabeitia, F. Moreno, B. L. Maroto, G. Muller, M. J. Ortiz and S. de la Moya, Chem.-Eur. J., 2015, 21, 13488; (b) J. Kumar, T. Nakashima and T. Kawai, J. Phys. Chem. Lett., 2015, 6, 3445. 